Public Abstract

First Name:Alexandra

Middle Name:

Last Name:Wayllace

Adviser's First Name:William

Adviser's Last Name:Likos

Co-Adviser's First Name:

Co-Adviser's Last Name:

Graduation Term:SP 2008

Department:Civil Engineering

Degree:PhD

\title{
Title:VOLUME CHANGE AND SWELLING PRESSURE OF EXPANSIVE CLAY IN THE CRYSTALLINE SWELLING REGIME
}

A significant amount of research has been carried out to characterize expansive clay behavior from either microstructural or macrostructural perspectives; however, there exists a current gap in our knowledge about the basic mechanisms that relate one structural level to another. This research investigates: how volume changes occurring on the interlayer scale upscale to volume change and swelling pressure for bulk particle systems, how variables such as void ratio, compaction conditions, particle and pore fabric, confining conditions, initial conditions, pore fluid chemistry, and clay chemistry govern this upscaling process, and what models are available to quantify these effects.

Three types of clay were used: Na-smectite, Ca-smectite, and a Ca-exchanged form of the Na-smectite. Results obtained include: SEM imaging of $\mathrm{Na}$ and $\mathrm{Ca}$ smectite, void ratio as a function of compaction pressure, water vapor sorption isotherms, axial deformation vs. relative humidity $(\mathrm{RH})$ during wetting and drying for free swell boundary conditions, and swelling pressure vs. $\mathrm{RH}$ for constant strain boundary conditions. Effects of initial density, interlayer cation, clay fabric, and stress paths were qualitatively analyzed in light of three conceptual models, and quantified by obtaining defining curves describing constitutive surfaces for the behavior of smectite in the crystalline swelling regime.

With better knowledge of how microstructural swelling translates to macroscopic behavior and what mechanisms and variables are important, the geotechnical engineering community and industry will be more equipped to approach and resolve the several problems involving expansive clays 